\title{
Comparison of the effect of continuous intravenous infusion and two bolus injections of remifentanil on haemodynamic responses during anaesthesia induction: a prospective randomised single-centre study
}

\author{
Toyoaki Maruta ${ }^{1 *}$, Yoshihumi Kodama², Ishie Tanaka ${ }^{3}$, Tetsuro Shirasaka ${ }^{1}$ and Isao Tsuneyoshi ${ }^{1}$
}

\begin{abstract}
Background: Remifentanil is an effective drug for protecting against adverse haemodynamic responses to tracheal intubation. We compared the haemodynamic responses during anaesthesia induction between continuous intravenous (IV) infusion and two bolus injections of remifentanil.

Methods: This prospective, randomised, open-label, single-centre study included patients with American Society of Anesthesiologists physical status I-II, scheduled to undergo elective surgery under general anaesthesia. Patients were randomised into two groups based on remifentanil administration type: the continuous IV infusion group (Group C) receiving a $0.3-\mu \mathrm{g} / \mathrm{kg} / \mathrm{min}$ remifentanil infusion for $5 \mathrm{~min}$ followed by a $0.1-\mu \mathrm{g} / \mathrm{kg} / \mathrm{min}$ remifentanil infusion, and the IV bolus group (Group B) receiving a combination of two bolus injections of remifentanil (first bolus of $0.4 \mu \mathrm{g} / \mathrm{kg}$ and second bolus of $0.6 \mu \mathrm{g} / \mathrm{kg}$ after $3 \mathrm{~min}$ ) and $0.1 \mu \mathrm{g} / \mathrm{kg} / \mathrm{min}$ remifentanil. General anaesthesia was induced with $1 \mathrm{mg} / \mathrm{kg}$ propofol and $0.6 \mathrm{mg} / \mathrm{kg}$ rocuronium $3 \mathrm{~min}$ after remifentanil infusion (Group C) or immediately after the first bolus of remifentanil (Group B). Tracheal intubation was performed 4 min after the injection of propofol and rocuronium. Heart rate and non-invasive blood pressure were recorded at 1-min intervals from baseline (i.e., before induction) to 5 min after tracheal intubation.
\end{abstract}

Results: A total of 107 patients were enrolled (Group C, 55; Group B, 52). Normotensive patients with no history of antihypertensive medication use were assigned to the normotensive subgroup (41 each in both groups), while those with hypertension but without a history of antihypertensive medication use were assigned to the untreated hypertensive subgroup (Group C vs. B, $n=7$ vs. 4). Finally, patients with a history of antihypertensive medication use were assigned to the treated hypertensive subgroup (7 each in both Groups $C$ and B). No differences in heart rate and blood pressure were observed between Groups $C$ and B within each subgroup.

Conclusions: Haemodynamic responses during anaesthesia induction were similar between continuous infusion and two bolus injections of remifentanil within both normotensive and hypertensive patients with or without medication.

Trial registration: The trial was retrospectively registered with Japanese Clinical Trial Registry "UMIN-CTR" on 20 October 2016 and was given a trial ID number UMIN000024495.

Keywords: Remifentanil, Anaesthesia induction, Laryngoscopy, Intubation, Prospective study

\footnotetext{
*Correspondence: mmctm2@yahoo.co.jp

'Department of Anesthesiology, Miyazaki Medical College, University of

Miyazaki, Miyazaki 889-1692, Japan

Full list of author information is available at the end of the article
} 


\section{Background}

Remifentanil is a rapid-onset and ultra-short acting opioid [1-3]. Since laryngoscopy and tracheal intubation can result in tachycardia and hypertension, remifentanil is commonly used not only to maintain anaesthesia, but also to attenuate adverse haemodynamic changes due to tracheal intubation [4-6]. To raise the effect-site concentration of remifentanil quickly, it is infused at higher concentrations or injected in bolus doses prior to constant continuous infusion. However, differences in haemodynamics during anaesthesia induction between continuous infusion and bolus injection of remifentanil have not yet been investigated. In addition, it remains unclear which method is best suited to hypertensive patients in whom tachycardia and hypertension by intubation may be exaggerated.

The aims of this randomised open-label study were to compare the haemodynamic responses during anaesthesia induction between continuous intravenous infusion and bolus injections of remifentanil in normotensive patients, as well as in treated and untreated hypertensive patients.

\section{Methods}

\section{Ethics and study design}

This study was approved by the hospital ethics committee for human studies (Ethical Committee number 2013-079; Chairperson Professor Koichiro Itai) on 3 October 2013, and all patients provided informed written consent. American Society of Anesthesiologists physical status (ASA) I-II patients scheduled for elective surgery under general anaesthesia were prospectively enrolled. Exclusion criteria included patients younger than 20 years of age and with the presence of cardiovascular or cerebrovascular disease, renal failure, or a predicted difficult airway. If tracheal intubation was not performed within $1 \mathrm{~min}$, this patient was excluded.

Normotensive patients with no history of antihypertensive medication use were assigned to the normotensive patients subgroup, while those with hypertension (systolic blood pressure $(\mathrm{SBP})>140 \mathrm{mmHg}$ ) were assigned to the untreated hypertensive (HT) patient subgroup. Hypertensive patients with a history of antihypertensive medication use were assigned to the treated HT patients subgroup. Using a stratified permuted block randomization method, normotensive patients were randomized to two groups of remifentanil administration type; the continuous intravenous (IV) infusion group (Group C) and the IV bolus group (Group B). Group C patients received a $0.3 \mu \mathrm{g} / \mathrm{kg} / \mathrm{min}$ infusion of remifentanil for five minutes followed by a $0.1 \mu \mathrm{g} / \mathrm{kg} / \mathrm{min}$ infusion of remifentanil, and Group B patients received a combination of two bolus injections of remifentanil (first bolus of $0.4 \mu \mathrm{g} / \mathrm{kg}$ and second bolus of $0.6 \mu \mathrm{g} / \mathrm{kg}$ in a $3 \mathrm{~min}$ interval) with $0.1 \mu \mathrm{g} / \mathrm{kg} / \mathrm{min}$ remifentanil. The treated HT and untreated HT patients were also randomized into two groups using a simple randomization method by random number tables. The time courses of anaesthesia induction in Group $\mathrm{C}$ and $\mathrm{B}$ are shown in Fig. 1. General anaesthesia was induced using $1 \mathrm{mg} / \mathrm{kg}$ propofol and $0.6 \mathrm{mg} / \mathrm{kg}$ rocuronium $3 \mathrm{~min}$ after infusion of remifentanil in Group $\mathrm{C}$ or immediately after the first bolus of remifentanil in Group B. An additional $10 \mathrm{mg}$ of propofol was administrated every $10 \mathrm{~s}$ until there was a loss of verbal response. Tracheal intubation was performed $4 \mathrm{~min}$ after induction of anaesthesia (7 min after the infusion of remifentanil in Group C or 4 min after the first bolus of remifentanil in Group B), at which estimated effect-site concentration of

\section{a) Group C}

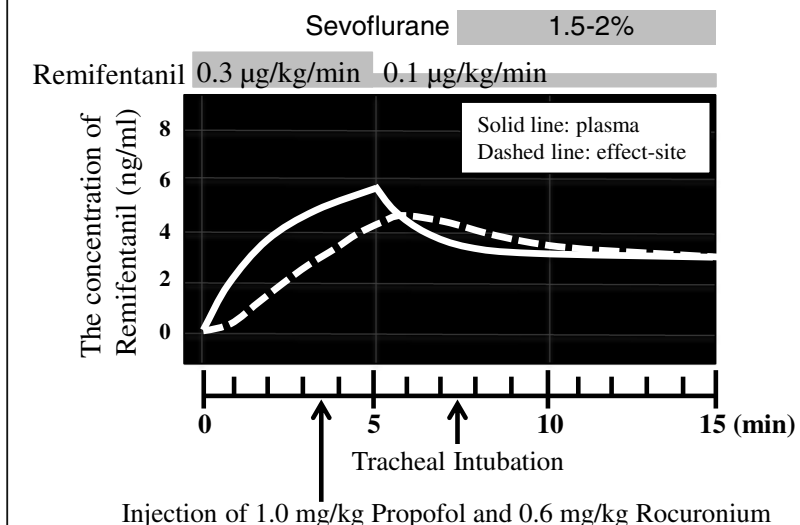

\section{b) Group B}

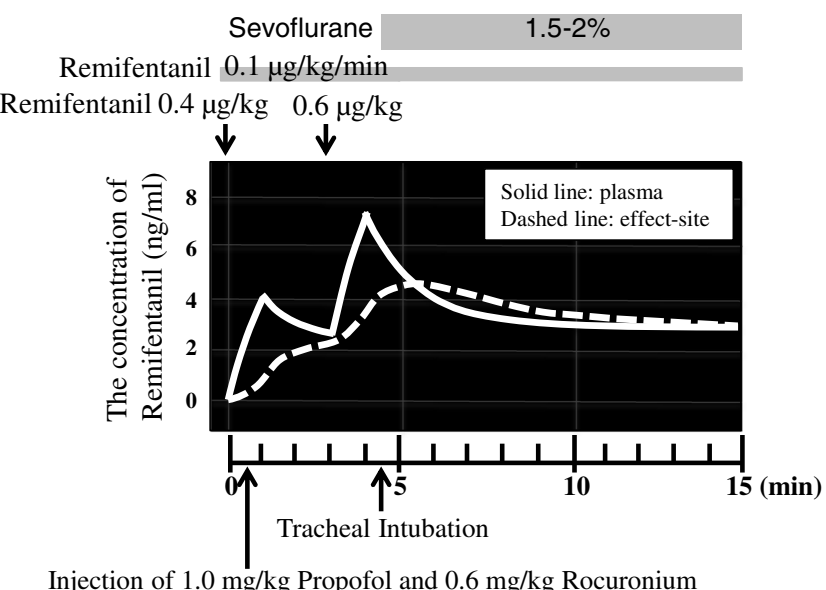

Injection of $1.0 \mathrm{mg} / \mathrm{kg}$ Propofol and $0.6 \mathrm{mg} / \mathrm{kg}$ Rocuronium

Fig. 1 The time course of plasma and effect-site concentration of remifentanil in Group C (a) and Group B (b). The plasma and effect-site concentrations of remifentanil were calculated using the Egan model, which was a default formula used in PrimeGaia, the electronic anaesthesia record 
Table 1 Data characteristics of patients, stratified by group

\begin{tabular}{|c|c|c|c|c|c|c|}
\hline \multirow[b]{2}{*}{ Subgroups } & \multicolumn{3}{|l|}{ Group C } & \multicolumn{3}{|l|}{ Group B } \\
\hline & $\begin{array}{l}\text { Normotensive } \\
(n=41)\end{array}$ & $\begin{array}{l}\text { Treated HT } \\
(n=7)\end{array}$ & $\begin{array}{l}\text { Untreated HT } \\
(n=7)\end{array}$ & $\begin{array}{l}\text { Normotensive } \\
(n=41)\end{array}$ & $\begin{array}{l}\text { Treated HT } \\
(n=7)\end{array}$ & $\begin{array}{l}\text { Untreated HT } \\
(n=4)\end{array}$ \\
\hline Age (year) & $46 \pm 16$ & $66 \pm 9$ & $57 \pm 13$ & $45 \pm 16$ & $67 \pm 5$ & $63 \pm 7$ \\
\hline Male/Female & $21 / 20$ & $4 / 3$ & $2 / 5$ & $21 / 20$ & $7 / 0$ & $2 / 2$ \\
\hline Height (cm) & $161 \pm 8$ & $158 \pm 8$ & $155 \pm 6$ & $162 \pm 8$ & $162 \pm 13$ & $160 \pm 15$ \\
\hline Weight (kg) & $57 \pm 10$ & $59 \pm 9$ & $55 \pm 5$ & $60 \pm 9$ & $66 \pm 13$ & $57 \pm 11$ \\
\hline BMI & $21.8 \pm 3.1$ & $23.7 \pm 3.5$ & $22.7 \pm 2.8$ & $22.7 \pm 2.8$ & $24.8 \pm 2.9$ & $22.3 \pm 1.0$ \\
\hline ASA I/II & $28 / 13$ & $0 / 7$ & $0 / 7$ & $27 / 14$ & $0 / 7$ & $0 / 4$ \\
\hline
\end{tabular}

The results are expressed as mean \pm SD or numbers of patients. Normotensive: patients with no history of antihypertensive medication use and with normotension, treated HT: patients with history of antihypertensive medication use, untreated HT: patients with no history of antihypertensive medication use and with hypertension, $H T$ hypertensive, BMI body mass index, ASA American Society of Anesthesiologists physical status

remifentanil was approximately $4 \mathrm{ng} / \mathrm{ml}$ in each group. After intubation, general anaesthesia was maintained with $1.5-2 \%$ inspired sevoflurane and $0.1 \mu \mathrm{g} /$ $\mathrm{kg} / \mathrm{min}$ remifentanil in both groups.

\section{Measurements}

Heart rate (HR) and non-invasive blood pressure (NIBP) were recorded at 1-min intervals from baseline (prior to induction) to 5 min after tracheal intubation. NIBP every $1 \mathrm{~min}$ is not always possible due to time taken for each measurement and has the potential to affect subsequent mesurements. However, it was considered that invasive blood pressure measurement was not suitable for this study, because almost patients were performed minor surgeries. If NIBP measurement was failed, this patient was excluded. If $\mathrm{HR}$ or SBP decreased to less than $50 \mathrm{bpm}$ or $70 \mathrm{mmHg}$ respectively, IV of $4 \mathrm{mg}$ ephedrine was deemed necessary. The estimated effect-site concentration of remifentanil was calculated with the Egan model [7] in the electronic Anaesthesia record "PrimeGaia" (Nihon Kohden, Tokyo, Japan).

\section{Statistical analysis}

A prior sample size calculation was performed, which revealed that 30 patients per group would have an $80 \%$ power with a $p<0.05$ to detect $15 \mathrm{mmHg}$ differences in mean arterial pressure between groups $(\alpha=$ $0.05, \beta=0.2$ ). All data are presented as mean \pm standard deviation (SD), numbers or percentage. Statistical analysis was performed using the program JMP 11 (SAS Institute Inc, Cary, NC, USA). Categorical data were examined using a chi-square test or Fisher's exact test to compare groups. One-way ANOVA for repeated measures was used to analyse changes over time. Significance $(p<0.05)$ was determined by oneway ANOVA with post hoc mean comparison by the Tukey-Kramer honestly significant difference (HSD) test. The student's $t$ test was used when means of two groups were compared.

\section{Results}

A total of 107 patients were recruited from October 2013 to June 2015. Patient characteristics are shown in Table 1 . There were 82 normotensive patients older than 20 years of age $(n=41$ in both groups), 14 treated HT patients ( $n=7$ in both groups) and 11 untreated HT patients $(n=7$ in Group $C$ and $n=4$ in Group B). Both the treated and untreated HT subgroups were compared between Group $\mathrm{C}$ and Group B. In both normotensive and treated HT patients, there were no significant differences between Group C and Group B in age, gender, height, weight, BMI, and ASA (Table 1). Anti-hypertensive medications which treated hypertension patients were taking are shown in Table 2. Ca blocker was continued through the morning of surgery, and angiotensin II receptor blocker was continued through the day before surgery. There were no significant differences between Group C and Group B in anti-hypertensive medications.

\section{Comparison of haemodynamic changes during anaesthesia induction between Group C and Group B} Comparisons of HR, SBP, diastolic blood pressure (DBP), and mean blood pressure (MBP) in normotensive patients between Group C and Group B are shown in Table 3 and illustrated in Fig. 2. There were

Table 2 Antihypertensive medication in treated hypertensive patients

\begin{tabular}{lll}
\hline & Group C & Group B \\
Subgroups & Treated HT $(n=7)$ & Treated HT $(n=7)$ \\
\hline Ca blocker & $5(72 \%)$ & $3(42 \%)$ \\
ARB & $1(14 \%)$ & $2(29 \%)$ \\
Ca blocker + ARB & $1(14 \%)$ & $2(29 \%)$
\end{tabular}

The results are expressed as numbers and \%. Ca blocker was continued through the morning of surgery, and ARB was continued through the day before surgery. Treated HT: patients with a history of antihypertensive medication use, $H T$ hypertensive, $A R B$ angiotensin II receptor blocker 
Table 3 Haemodynamic data during anaesthesia induction

\begin{tabular}{|c|c|c|c|c|c|c|c|}
\hline \multicolumn{2}{|l|}{ Subgroups } & \multicolumn{2}{|c|}{ Normotensive } & \multicolumn{2}{|c|}{ Treated HT } & \multicolumn{2}{|c|}{ Untreated HT } \\
\hline & & $\begin{array}{l}\text { Group C } \\
(n=41)\end{array}$ & $\begin{array}{l}\text { Group B } \\
(n=41)\end{array}$ & $\begin{array}{l}\text { Group C } \\
(n=7)\end{array}$ & $\begin{array}{l}\text { Group B } \\
(n=7)\end{array}$ & $\begin{array}{l}\text { Group C } \\
(n=7)\end{array}$ & $\begin{array}{l}\text { Group B } \\
(n=4)\end{array}$ \\
\hline \multirow[t]{8}{*}{ HR (bpm) } & Baseline & $70 \pm 8$ & $74 \pm 13$ & $68 \pm 19$ & $77 \pm 12$ & $74 \pm 23$ & $70 \pm 10$ \\
\hline & $\mathrm{T}_{\text {ind }}$ & $62 \pm 10$ & $67 \pm 10$ & $59 \pm 9$ & $64 \pm 11$ & $61 \pm 17$ & $62 \pm 10$ \\
\hline & TO & $77 \pm 20$ & $80 \pm 16$ & $72 \pm 15$ & $68 \pm 13$ & $66 \pm 11$ & $87 \pm 18$ \\
\hline & $\mathrm{T} 1$ & $76 \pm 13$ & $77 \pm 12$ & $72 \pm 15$ & $82 \pm 16$ & $74 \pm 20$ & $80 \pm 15$ \\
\hline & $\mathrm{T} 2$ & $72 \pm 10$ & $74 \pm 13$ & $68 \pm 14$ & $78 \pm 18$ & $69 \pm 19$ & $73 \pm 14$ \\
\hline & T3 & $70 \pm 9$ & $71 \pm 11$ & $69 \pm 13$ & $72 \pm 17$ & $66 \pm 16$ & $70 \pm 12$ \\
\hline & $\mathrm{T} 4$ & $68 \pm 10$ & $70 \pm 11$ & $67 \pm 11$ & $70 \pm 13$ & $66 \pm 17$ & $66 \pm 9$ \\
\hline & $\mathrm{T} 5$ & $67 \pm 10$ & $70 \pm 10$ & $66 \pm 11$ & $71 \pm 19$ & $61 \pm 13$ & $68 \pm 9$ \\
\hline \multirow[t]{8}{*}{$\mathrm{SBP}(\mathrm{mmHg})$} & Baseline & $123 \pm 14$ & $122 \pm 13$ & $145 \pm 19$ & $136 \pm 19$ & $153 \pm 9$ & $154 \pm 11$ \\
\hline & $\mathrm{T}_{\text {ind }}$ & $81 \pm 18^{*}$ & $80 \pm 12^{*}$ & $79 \pm 16^{*}$ & $80 \pm 21^{*}$ & $93 \pm 14^{*}$ & $100 \pm 16^{*}$ \\
\hline & TO & $92 \pm 30^{*}$ & $100 \pm 17^{*}$ & $97 \pm 20^{*}$ & $98 \pm 26^{*}$ & $109 \pm 36^{*}$ & $153 \pm 40$ \\
\hline & $\mathrm{T} 1$ & $96 \pm 25^{*}$ & $107 \pm 18^{*}$ & $107 \pm 23^{*}$ & $124 \pm 41$ & $133 \pm 42$ & $147 \pm 15$ \\
\hline & $\mathrm{T} 2$ & $94 \pm 25^{*}$ & $101 \pm 15^{*}$ & $103 \pm 22^{*}$ & $122 \pm 46$ & $123 \pm 42$ & $151 \pm 46$ \\
\hline & T3 & $88 \pm 18^{*}$ & $96 \pm 20^{*}$ & $104 \pm 21^{*}$ & $115 \pm 30$ & $112 \pm 40^{*}$ & $123 \pm 17$ \\
\hline & $\mathrm{T} 4$ & $86 \pm 16^{*}$ & $93 \pm 20^{*}$ & $96 \pm 15^{*}$ & $109 \pm 26^{*}$ & $111 \pm 37^{*}$ & $116 \pm 21^{*}$ \\
\hline & $\mathrm{T} 5$ & $87 \pm 17^{*}$ & $90 \pm 17^{*}$ & $95 \pm 15^{*}$ & $102 \pm 19^{*}$ & $106 \pm 31^{*}$ & $115 \pm 10^{*}$ \\
\hline \multirow[t]{8}{*}{$\mathrm{DBP}(\mathrm{mmHg})$} & Baseline & $76 \pm 14$ & $77 \pm 14$ & $82 \pm 19$ & $82 \pm 7$ & $86 \pm 9$ & $92 \pm 11$ \\
\hline & $\mathrm{T}_{\text {ind }}$ & $47 \pm 14^{*}$ & $49 \pm 10^{*}$ & $48 \pm 15^{*}$ & $51 \pm 9^{*}$ & $50 \pm 7^{*}$ & $66 \pm 17^{*}$ \\
\hline & TO & $61 \pm 23$ & $66 \pm 17$ & $62 \pm 17$ & $65 \pm 13^{*}$ & $70 \pm 32$ & $99 \pm 25$ \\
\hline & $\mathrm{T} 1$ & $62 \pm 23$ & $69 \pm 16$ & $68 \pm 16$ & $75 \pm 22$ & $75 \pm 31$ & $96 \pm 21$ \\
\hline & $\mathrm{T} 2$ & $58 \pm 19$ & $66 \pm 17^{*}$ & $62 \pm 14^{*}$ & $74 \pm 20$ & $70 \pm 27$ & $86 \pm 26$ \\
\hline & $\mathrm{T} 3$ & $55 \pm 16^{*}$ & $62 \pm 16^{*}$ & $61 \pm 12^{*}$ & $68 \pm 15^{*}$ & $63 \pm 24^{*}$ & $77 \pm 17$ \\
\hline & T4 & $53 \pm 14^{*}$ & $59 \pm 17^{*}$ & $58 \pm 10^{*}$ & $68 \pm 15^{*}$ & $60 \pm 21^{*}$ & $73 \pm 16$ \\
\hline & $\mathrm{T} 5$ & $52 \pm 12^{*}$ & $57 \pm 15^{*}$ & $57 \pm 10^{*}$ & $62 \pm 7^{*}$ & $57 \pm 19^{*}$ & $72 \pm 11^{*}$ \\
\hline \multirow[t]{8}{*}{$\mathrm{MBP}(\mathrm{mmHg})$} & Baseline & $90 \pm 11$ & $89 \pm 10$ & $101 \pm 29$ & $97 \pm 6$ & $105 \pm 12$ & $114 \pm 14$ \\
\hline & $\mathrm{T}_{\text {ind }}$ & $58 \pm 12^{*}$ & $59 \pm 10^{*}$ & $57 \pm 15^{*}$ & $59 \pm 14^{*}$ & $66 \pm 11^{*}$ & $73 \pm 19^{*}$ \\
\hline & TO & $73 \pm 22$ & $78 \pm 19$ & $73 \pm 17^{*}$ & $73 \pm 16^{*}$ & $82 \pm 31$ & $115 \pm 32$ \\
\hline & $\mathrm{T} 1$ & $72 \pm 18$ & $79 \pm 16$ & $80 \pm 17$ & $92 \pm 27$ & $92 \pm 36$ & $111 \pm 14$ \\
\hline & $\mathrm{T} 2$ & $68 \pm 16^{*}$ & $77 \pm 18^{*}$ & $75 \pm 17$ & $91 \pm 36$ & $88 \pm 30$ & $100 \pm 31$ \\
\hline & $\mathrm{T} 3$ & $65 \pm 14^{*}$ & $73 \pm 16^{*}$ & $72 \pm 15^{*}$ & $83 \pm 21$ & $81 \pm 24^{*}$ & $89 \pm 20$ \\
\hline & T4 & $64 \pm 12^{*}$ & $71 \pm 20^{*}$ & $69 \pm 11^{*}$ & $78 \pm 15^{*}$ & $80 \pm 26^{*}$ & $88 \pm 15^{*}$ \\
\hline & $\mathrm{T} 5$ & $62 \pm 11^{*}$ & $69 \pm 16^{*}$ & $68 \pm 10^{*}$ & $74 \pm 12^{*}$ & $76 \pm 20^{*}$ & $87 \pm 13^{*}$ \\
\hline
\end{tabular}

The results are expressed as mean \pm SD. Haemodynamic variables were recorded before induction of general anaesthesia (baseline), immediately before tracheal intubation ( $\left.\mathrm{T}_{\text {ind }}\right)$, immediately after tracheal intubation (T0), and every minute for 5 min following tracheal intubation (T1-T5)

${ }^{*} p<0.05$, compared with baseline within each group

$H R$ heart rate, $S B P$ systolic blood pressure, $D B P$ diastolic blood pressure, $M B P$ mean blood pressure

no significant differences between the groups for any parameters at any time points. When compared to baseline, HR was not significantly different at any time points in either group; however, upon comparison between immediately before tracheal intubation $\left(\mathrm{T}_{\text {ind }}\right)$ and immediately after tracheal intubation (T0),
SBP, DBP, and MBP were significantly decreased compared to baseline in each group.

Comparisons of HR, SBP, DBP, and MBP within treated and untreated HT patients between Group C and Group B are shown in Table 3 and illustrated in Figs. 3 and 4, respectively. There were no significant 

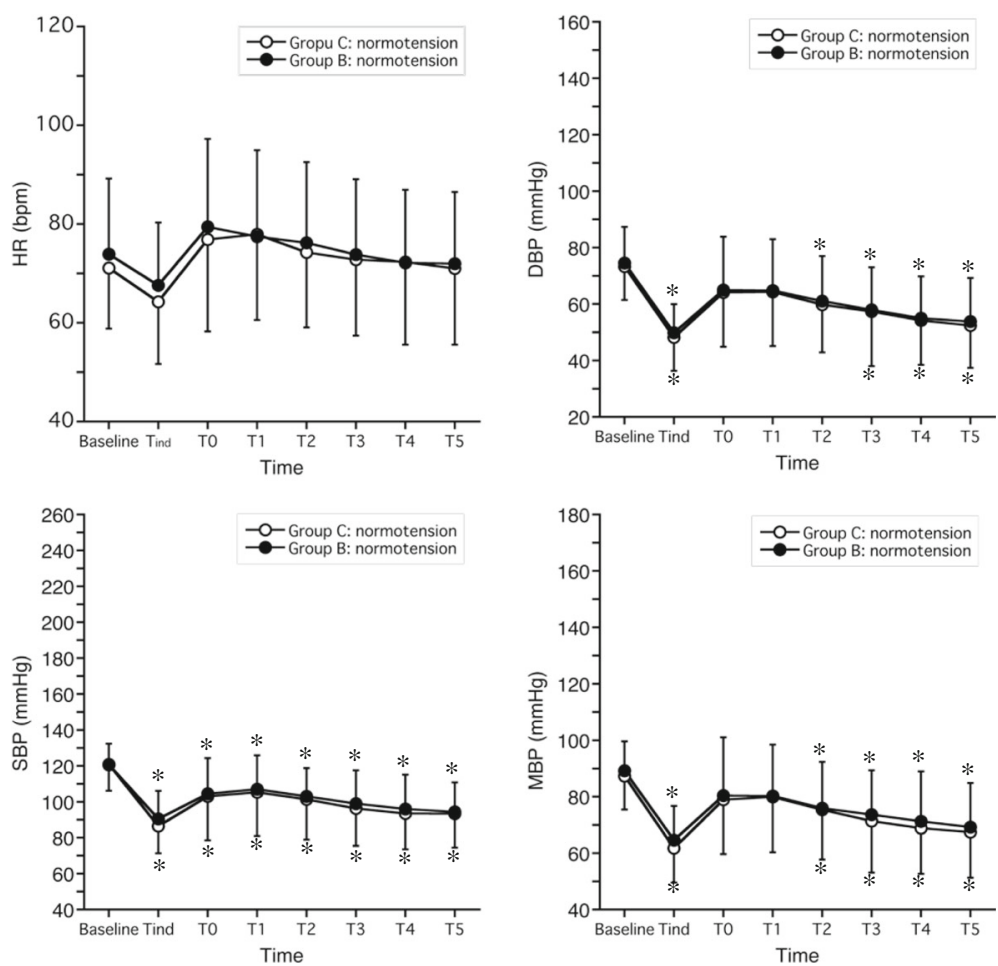

Fig. 2 Heart rate (HR), systolic blood pressure (SBP), diastolic blood pressure (DBP), and mean blood pressure (MBP), stratified by group, for normotensive patients (mean \pm SD). Haemodynamic variables were recorded before induction of general anaesthesia (baseline), immediately before tracheal intubation $\left(T_{\text {ind }}\right)$, immediately after tracheal intubation $(T 0)$, and every minute for 5 min following tracheal intubation $(T 1-T 2) .{ }^{*} p<0.05$, compared with baseline within each group

differences between groups for any parameters at any time points in each subgroup.

\section{Use of additional propofol and adverse events}

Use of additional propofol and adverse events including $\mathrm{HR}<50 \mathrm{bpm}, \mathrm{SBP}<70 \mathrm{mmHg}$, and use of ephedrine are shown in Table 4 and illustrated in Fig. 5. There were no significant differences between groups in each subgroup. In normotensive patients, $55 \%$ of patients in Group $\mathrm{C}$ required additional propofol, compared to 59 \% of patients in Group B. Additionally, when age was categorized, patients younger than 60 years required more propofol (Group C vs. Group B: $20-29$ years old: $86 \%$ vs. $63 \%, 30-39: 75 \%$ vs. $63 \%, 40-49: 56 \%$ vs. $100 \%, 50-59: 45 \%$ vs. $55 \%$, over 60: $0 \%$ vs. $14 \%$ ). In the untreated HT subgroup, SBP was never under $70 \mathrm{mmHg}$ and ephedrine was never used.

\section{Discussion}

In this study, we demonstrated that a $0.3-\mu \mathrm{g} / \mathrm{kg} / \mathrm{min}$ infusion of remifentanil for $5 \mathrm{~min}$ followed by a 0.1 $\mu \mathrm{g} / \mathrm{kg} / \mathrm{min}$ infusion did not differ significantly from a combination of two bolus injections of remifentanil (first bolus of $0.4 \mu \mathrm{g} / \mathrm{kg}$ and second bolus of $0.6 \mu \mathrm{g} /$ $\mathrm{kg}$ after $3 \mathrm{~min}$ ) and $0.1-\mu \mathrm{g} / \mathrm{kg} / \mathrm{min}$ infusion of remifentanil in terms of haemodynamic responses during the induction of anaesthesia, in both normotensive patients and patients with hypertension, with or without treatment. In both remifentanil groups, HR deceased following anaesthesia induction and increased after intubation when compared to baseline HR; however, this was not significant. Blood pressure was significantly decreased from baseline after anaesthesia induction and once increased upon intubation, but again decreased from baseline after intubation. However, these changes in blood pressure were not considered clinically significant. In the treated and untreated HT patients, Group C maintained baseline blood pressure after intubation for longer than Group B.

The cardiovascular response to anaesthesia induction, laryngoscopy, and tracheal intubation may be exaggerated in the treated or untreated HT patients [8]. Maguire et al. reported that a bolus dose of remifentanil $0.5 \mu \mathrm{g} / \mathrm{kg}$ followed by a $0.1 \mu \mathrm{g} / \mathrm{kg} / \mathrm{min}$ infusion 

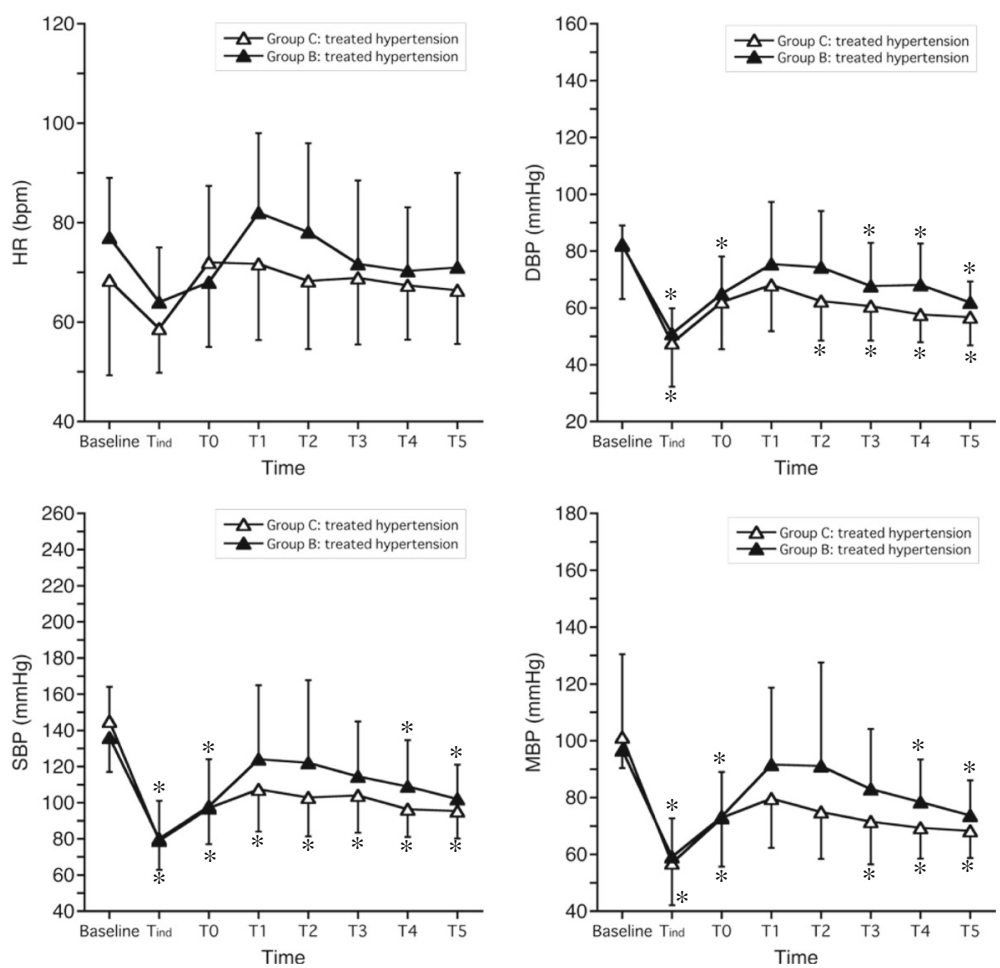

Fig. 3 Heart rate (HR), systolic blood pressure (SBP), diastolic blood pressure (DBP), and mean blood pressure (MBP), stratified by group, for treated hypertensive patients (mean \pm SD). Haemodynamic variables were recorded before induction of general anaesthesia (baseline), immediately before tracheal intubation $\left(T_{\text {ind }}\right)$, immediately after tracheal intubation (T0), and every minute for 5 min following tracheal intubation (T1-T2). ${ }^{*} p<0.05$, compared with baseline within each group

could well control the haemodynamic response to intubation in treated HT patients. However, the increase in blood pressure was approximately $30 \mathrm{mmHg}$ during this regimen, compared to a $10 \mathrm{mmHg}$ increase in young adults who received a bolus dose of remifentanil $0.5 \mu \mathrm{g} / \mathrm{kg}$ followed by a $0.25 \mu \mathrm{g} / \mathrm{kg} / \mathrm{min}$ infusion [8]. Park et al. demonstrated that a low-dose regimen of remifentanil, consisting of a $0.5 \mu \mathrm{g} / \mathrm{kg}$ bolus followed by a continuous infusion of $0.1 \mu \mathrm{g} / \mathrm{kg} /$ min, resulted in similar haemodynamic responses to induction and tracheal intubation in normotensive and treated or untreated HT patients, however untreated HT patients were shown to have a relatively large amplitude of pressure swing [9]. Our study also demonstrated that hypertensive patients had larger swings in haemodynamic response to anaesthesia induction and tracheal intubation than normotensive patients; conversely, untreated HT patients had no adverse hypotension $(\mathrm{SBP}<70 \mathrm{mmHg})$ in either group, whereas 2 of treated HT patients $(29 \%)$ had adverse hypotension in each group. Treated HT patients might be easy to have $\mathrm{SBP}<70 \mathrm{mmHg}$, because SBP at baseline in treated HT was lower than that in untreated $\mathrm{HT}$ and the haemodynamic depression in response to anaesthesia induction were not different between treated HT and untreated HT, as shown in Table 3. On the basis of these findings, the low-dose regimen of remifentanil was also shown to be effective at stabilizing haemodynamics prior to intubation, and limiting pressure responses to tracheal intubation without excessive cardiovascular depression. Besides, the remifentanil administration methods to 2 groups in this study were also low-dose regimens like those of Maguire and Park's reports.

Remifentanil is a rapid-onset and ultra-short acting pain relief opioid. Although multiple drugs such as lidocaine [10], opioids $[8,11,12], \beta$-blockers $[13,14]$, dexmedetomidine [15] and volatile anaesthetics [16] can be used to attenuate tachycardia and hypertension due to tracheal intubation, remifentanil is considered to have the ideal pharmacological character to treat adverse haemodynamic response due to a noxious but brief stimulation of tracheal intubation. However, much higher rates of infusion or bolus doses of remifentanil than those used in our study were associated to bradycardia and/or hypotension [4, 5]. The separated bolus method of Group B may be effective in avoiding excessive cardiovascular depression before intubation. 

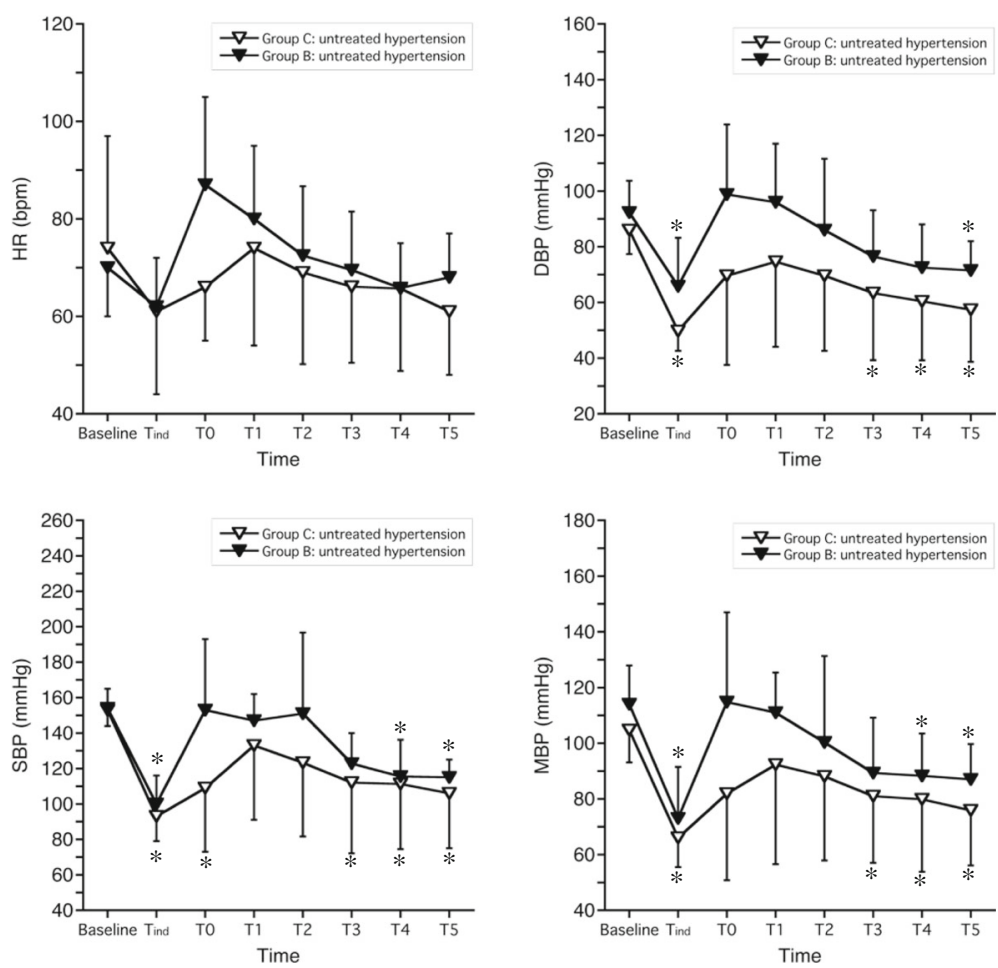

Fig. 4 Heart rate (HR), systolic blood pressure (SBP), diastolic blood pressure (DBP), and mean blood pressure (MBP), stratified by group, for untreated hypertensive patients (mean \pm SD). Haemodynamic variables were recorded before induction of general anaesthesia (baseline), immediately before tracheal intubation $\left(T_{\text {ind }}\right)$, immediately after tracheal intubation (T0), and every minute for 5 min following tracheal intubation (T1-T5). ${ }^{*} p<0.05$, compared with baseline within each group

General anaesthesia was induced with $1 \mathrm{mg} / \mathrm{kg}$ propofol and $0.6 \mathrm{mg} / \mathrm{kg}$ rocuronium, and an additional $10 \mathrm{mg}$ of propofol was administrated every $10 \mathrm{~s}$ until there was a loss of verbal response. Although standard propofol dose at induction is $1.5-2.5 \mathrm{mg} / \mathrm{kg}$, opioids reduce requirement dose of propofol for loss of consciousness. In combination with remifantanil, 1.0$1.5 \mathrm{mg}$ propofol is sufficient for loss of consciousness $[17,18]$. The need for additional propofol was similar between groups. When age was categorized, patients younger than 60 years required more propofol, suggesting that $1 \mathrm{mg} / \mathrm{kg}$ of propofol may not to be enough for anaesthesia induction in patients under 60 years old even with remifentanil administration. However, due to the individual minimum necessary amount of propofol used for the anaesthesia induction, the suppressive effect of propofol on haemodynamics may be limited in this study.

Thompson et al. reported that $50 \%$ of patients who received $1 \mu \mathrm{g} / \mathrm{kg}$ of remifentanil followed by an infusion of $0.5 \mu \mathrm{g} / \mathrm{kg} / \mathrm{min}$, exhibited bradycardia (HR $<45 \mathrm{bpm}$ ) and hypotension ( $\mathrm{SBP}<80 \mathrm{mmHg}$ ), and required rescue medication [4]. In this study, adverse events such as bradycardia $(\mathrm{HR}<50 \mathrm{bpm})$ and

Table 4 Use of additional propofol and adverse events in patients, stratified by group

\begin{tabular}{|c|c|c|c|c|c|c|}
\hline \multirow[b]{2}{*}{ Subgroups } & \multicolumn{3}{|l|}{ Group C } & \multicolumn{3}{|l|}{ Group B } \\
\hline & $\begin{array}{l}\text { Normotensive } \\
(n=41)\end{array}$ & $\begin{array}{l}\text { Treated HT } \\
(n=7)\end{array}$ & $\begin{array}{l}\text { Untreated HT } \\
(n=7)\end{array}$ & $\begin{array}{l}\text { Normotensive } \\
(n=41)\end{array}$ & $\begin{array}{l}\text { Treated HT } \\
(n=7)\end{array}$ & $\begin{array}{l}\text { Untreated HT } \\
(n=4)\end{array}$ \\
\hline Additional Propofol & $22(55 \%)$ & $2(29 \%)$ & $4(57 \%)$ & $24(59 \%)$ & $0(0 \%)$ & $1(25 \%)$ \\
\hline \multicolumn{7}{|l|}{ Adverse Events } \\
\hline $\mathrm{HR}<50 \mathrm{bpm}$ & $3(8 \%)$ & $1(14 \%)$ & $2(29 \%)$ & $3(7 \%)$ & $2(29 \%)$ & $0(0 \%)$ \\
\hline $\mathrm{SBP}<70 \mathrm{mmHg}$ & $8(20 \%)$ & $2(29 \%)$ & $0(0 \%)$ & $9(22 \%)$ & $2(29 \%)$ & $0(0 \%)$ \\
\hline Use of Ephedrine & $8(20 \%)$ & $2(29 \%)$ & $0(0 \%)$ & $4(10 \%)$ & $2(29 \%)$ & $0(0 \%)$ \\
\hline
\end{tabular}

The results are expressed as numbers and \%. Normotensive: patients with no history of antihypertensive medication use and with normotension, treated HT: patients with a history of antihypertensive medication use, untreated HT: patients with no history of antihypertensive medication use and with hypertension, HT hypertensive 


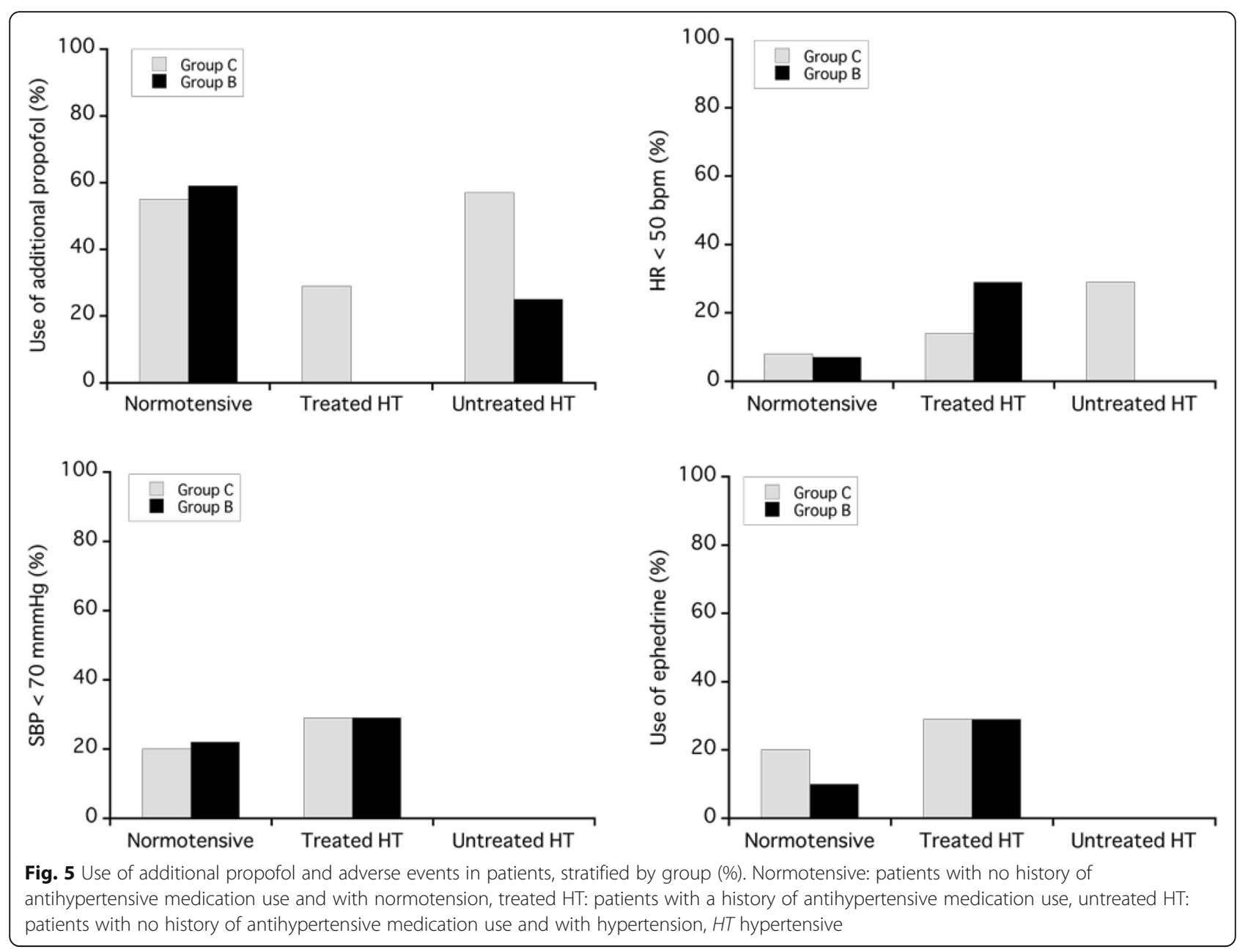

hypotension ( $\mathrm{SBP}<70 \mathrm{mmHg}$ ) were similar between groups. In both groups and subgroups, adverse events occurred in less than $30 \%$ of patients. This lower incidence of adverse events could be related to the lower infusion regimen and the separated bolus injections.

\section{Limitations}

The Egan model was used to estimate plasma and effect-cite concentration of remifentanil. In comparison to the Minto model [19], which is commonly used to estimate remifentanil concentration, the Egan model is not corrected for age. Hence, in the elderly, the actual remifentanil concentration can be higher than the estimated concentration. In addition, we used actual weight to determine the dose of remifentanil to be administered as it has been reported that ideal body weight-based remifentanil infusion is potentially insufficient for anaesthetic induction in obese patients [20]. The sample sizes of treated and untreated HT subgroups were small and a larger randomized study is needed to confirm these results.

\section{Conclusions}

Both the continuous and bolus regimen of remifentanil reduced haemodynamic responses to intubation effectively, and resulted in similar haemodynamics during induction of anaesthesia within normotensive and hypertensive patients with or without antihypertensive medication. In other words, separated remifentanil boluses method was performed as safely as continuous infusion method and would be able to reduce time spent on anesthesia induction compared to continuous infusion.

\section{Abbreviations}

ASA: American society of Anesthesiologists; DBP: Diastolic blood pressure; HR: Heart rate; HT: Hypertensive; MBP: Mean blood pressure; SBP: Systolic blood pressure; SD: Standard deviation

\section{Acknowledgments}

This study was attributed to Department of Anesthesiology, Miyazaki Medical College, University of Miyazaki. The authors would like to thank Noriko Hidaka and Toshiko Watanabe for their assistance in the collection with the study.

Funding

This study was not funded by any funding agencies. 


\section{Availability of data and materials}

The dataset supporting the conclusions of this article is available in https://figshare.com/s/1a181df2bff05006b527.

\section{Authors' contributions}

TM designed and conducted the study, analysed the data, and wrote the manuscript. YK and IT helped recruit the study patients and collect the data. TS \& IT helped design and conduct the study and analyse the data, and edited the manuscript. All authors read and approved the final manuscript.

\section{Competing interests}

The authors declare that they have no competing interests.

\section{Consent for publication}

Not applicable.

\section{Ethics approval and consent to participate}

This study was approved by the hospital ethics committee for human studies (Ethical Committee number 2013-079; Chairperson Professor Koichiro Itai) on 3 October 2013, and all patients provided informed written consent.

\section{Presentation}

Results of this trial are presented at Annual Meeting of the Japanese Society of Anesthesiologists 2015, Kobe as a poster.

\section{Author details}

'Department of Anesthesiology, Miyazaki Medical College, University of Miyazaki, Miyazaki 889-1692, Japan. ${ }^{2}$ Department of Anesthesiology, Miyazaki Medical Association Hospital, Miyazaki 880-0834, Japan. ${ }^{3}$ Department of Internal Medicine, Koga General Hospital, Miyazaki 880-0041, Japan.

Received: 18 May 2016 Accepted: 25 October 2016

\section{Published online: 14 November 2016}

\section{References}

1. Egan TD, Lemmens HJ, Fiset P, Hermann DJ, Muir KT, Stanski DR, Shafer SL. The pharmacokinetics of the new short-acting opioid remifentanil (Gl87084B) in healthy adult male volunteers. Anesthesiology. 1993;79:881-92.

2. Bürkle H, Dunbar S, Van Aken H. Remifentanil: a novel, short-acting, mu-opioid. Anesth Analg. 1996;83:646-51.

3. Glass PSA, Gan TJ, Howell S. A review of the pharmacokinetics and pharmacodynamics of remifentanil. Anesth Analg. 1999;89:S7-14.

4. Thompson JP, Hall AP, Russell J, Cagney B, Rowbotham DJ. Effect of remifentanil on the haemodynamic response to orotracheal intubation. $\mathrm{Br} J$ Anaesth. 1998;80:467-9.

5. O'Hare R, McAtamney D, Mirakhur RK, Hughes D, Carabine U. Bolus dose remifentanil for control of haemodynamic response to tracheal intubation during rapid sequence induction of anaesthesia. $\mathrm{Br} J$ Anaesth. 1999;82(2):283-5.

6. Hall AP, Thompson JP, Leslie NA, Fox AJ, Kumar N, Rowbotham DJ. Comparison of different doses of remifentanil on the cardiovascular response to laryngoscopy and tracheal intubation. $\mathrm{Br} J$ Anaesth. 2000;84:100-2.

7. Egan TD, Minto CF, Hermann DJ, Barr J, Muir KT, Shafer SL. Remifentanil versus alfentanil: comparative pharmacokinetics and pharmacodynamics in healthy adult male volunteers. Anesthesiology. 1996;84:821-33.

8. Maguire AM, Kumar N, Parker JL, Rowbotham DJ, Thompson JP. Comparison of effects of remifentanil and alfentanil on cardiovascular response to tracheal intubation in hypertensive patients. $\mathrm{Br} J$ Anaesth. 2001;86:90-3.

9. Park SJ, Shim YH, Yoo JH, Nam SH, Lee JW. Low-dose remifentanil to modify haemodynamic responses to tracheal intubation: comparison in normotensive and untreated/treated hypertensive Korean patients. Korean J Anesthesiol. 2012;62:135-41.

10. Qi DY, Wang K, Zhang H, Du BX, Xu FY, Wang L, Zou Z, Shi XY. Efficacy of intravenous lidocaine versus placebo on attenuating cardiovascular response to laryngoscopy and tracheal intubation: a systematic review of randomised controlled trials. Minerva Anestesiol. 2013;79:1423-35.

11. Crawford DC, Fell D, Achola KJ, Smith G. Effects of alfentanil on the pressor and catecholamine responses to tracheal intubation. Br J Anaesth. 1987;59:707-12.
12. Habib AS, Parker JL, Maguire AM, Rowbotham DJ, Thompson JP. Effects of remifentanil and alfentanil on the cardiovascular responses to induction of anaesthesia and tracheal intubation in the elderly. Br J Anaesth. 2002;88:430-3.

13. Inoue $\mathrm{S}$, Tanaka $\mathrm{Y}$, Kawaguchi M, Furuya $\mathrm{H}$. The efficacy of landiolol for suppressing the hyperdynamic response following laryngoscopy and tracheal intubation: a systematic review. Anaesth Intensive Care. 2009;37:893-902.

14. Vucevic M, Purdy GM, Ellis FR. Esmolol hydrochloride for management of the cardiovascular stress responses to laryngoscopy and tracheal intubation. Br J Anaesth. 1992;68:529-30.

15. Kunisawa T, Nagata O, Nagashima M, Mitamura S, Ueno M, Suzuki A, Takahata O, Iwasaki H. Dexmedetomidine suppresses the decrease in blood pressure during anesthetic induction and blunts the cardiovascular response to tracheal intubation. J Clin Anesth. 2009;21:194-9.

16. Randell T, Seppälä T, Lindgren L. Isoflurane in nitrous oxide and oxygen increases plasma concentrations of noradrenaline but attenuates the pressor response to intubation. Acta Anaesthesiol Scand. 1991;35:600-5.

17. Conway DH, Hasan SK, Simson ME. Target-controlled propofol requirements at induction of anaesthesia: effect of remifentanil and midazolam. Eur J Anaesthesiol. 2002;19:580-4.

18. Jee YS, Hong JY. Effects of remifentanil on propofol requirements for loss of consciousness in target-controlled infusion. Minerva Anestesiol. 2008;74:17-22.

19. Minto CF, Schnider TW, Egan TD, Youngs E, Lemmens HJ, Gambus PL, Billard V, Hoke JF, Moore KH, Hermann DJ, Muir KT, Mandema JW, Shafer SL. Influence of ageand gender on the pharmacokinetics and pharmacodynamics of remifentanil. I Model development. Anesthesiology. 1997:86:10-23.

20. Kunisawa T, Mitamura S, Hanada S, Suzuki A, Takahata O, Iwasaki H. Ideal body weight-based remifentanil infusion is potentially insufficient for anesthetic induction in mildly obese patients. J Anesth. 2012;26:790-3.

\section{Submit your next manuscript to BioMed Central and we will help you at every step:}

- We accept pre-submission inquiries

- Our selector tool helps you to find the most relevant journal

- We provide round the clock customer support

- Convenient online submission

- Thorough peer review

- Inclusion in PubMed and all major indexing services

- Maximum visibility for your research

Submit your manuscript at www.biomedcentral.com/submit
) Biomed Central 